\title{
Quantitative Electron Probe Microanalysis at Age 60: A Still Vibrant and Evolving Nanoanalytical Method Fulfilling Castaing's Vision
}

\author{
John T. Armstrong* \\ *Geophysical Laboratory, Carnegie Institution of Washington, 5251 Broad Branch Road, NW, \\ Washington, DC 20015
}

When the 1999 Microscopy and Microanalysis Meeting celebrated the $50^{\text {th }}$ Anniversary of Castaing's construction of the first electron microprobe and publication of his remarkable $\mathrm{PhD}$ dissertation establishing this important analytical method, this author and others evaluated the current "state-ofthe-art" [e.g., 1]. High precision measurements made at a widening range of electron beam energies - enabled by the improved electronics and light element crystals of newer microprobes - showed reproducible discrepancies in the analyses of standards which indicated that the quality of the compositional standards and correction procedures (including the values of the physical parameters they utilized) needed further refinement. A variety of new correction algorithms had been proposed and tested in the previous decade and were now being applied for growingly more difficult analytical systems including analysis of layered specimens, surface coatings and microparticulates [e.g., 2]. The challenge remained to determine which of these to apply to the growing variety of difficult samples and the magnitude of uncertainty to expect when applying non-optimized corrections [3].

A decade later, the electron microprobe remains the premier tool for high-precision, high-accuracy quantitative microanalysis. Its capabilities have continued to evolve with microprobes dedicated to improved trace element analysis, larger area crystals, field emission guns, silicon drift EDS detectors (SDD), and combined hyperspectral compositional mapping using WDS and SDD detectors. We will examine the new level of precision and accuracy that can be obtained for major and minor elements with SDD analysis compared to that with WDS. Table 1 shows typical results obtained in our laboratory, showing comparable accuracy - which can result in more efficient use of WDS spectrometers for trace element, overlap line, and soft-x-ray analysis. Field emission guns enable low voltage analysis with highly focused beams at moderate to high beam currents. Combined with SDD and large area WDS spectrometers, low voltage analysis can reduce the analytical volume by a factor of $>10^{4}$, greatly improving analysis of small precipitates and surface layers [Fig. 1]. Results in our laboratory indicate that high accuracy and high precision analyses can be performed on field emission instruments at voltages as low as $3 \mathrm{keV}$ [e.g., Table 2]. However, these new capabilities require continuation of the evaluation, testing and refinement of the analytical methods and correction parameters and algorithms as discussed a decade ago.

\section{References}

[1] J. T. Armstrong Microsc. Microanal. $\underline{5}$ (suppl. 2) (1999) 560.

[2] K. F. J. Heinrich and D. E. Newbury, Eds., Electron Probe Quantitation, Plenum Press (1991); e.g., J. T. Armstrong, ibid., 261.

[3] J. T. Armstrong, Microbeam Analysis 4, (1995) 177.

[4] R. Gauvin et al., Micros. Microanaly. 12, (2006) 49.

[5] This research was supported in part by endowment funds from the Carnegie Institution of Washington and by instrumentation funds from NSF MRI grant EAR-0923127. 
TABLE 1. Comparison of SDD-EDS and WDS analyses of augite standard $(15 \mathrm{keV})$

\begin{tabular}{crrrrrrr}
\hline & \multicolumn{7}{c}{ Element Weight \% } \\
\cline { 2 - 8 } El. & Actual & \multicolumn{3}{c}{ SDD-EDS } & \multicolumn{4}{c}{ WDS-EPMA } \\
\hline $\mathrm{Na}$ & 0.62 & 0.57 & \pm & 0.02 & 0.61 & \pm & 0.02 \\
$\mathrm{Mg}$ & 10.44 & 10.46 & \pm & 0.04 & 10.36 & \pm & 0.04 \\
$\mathrm{Al}$ & 3.94 & 3.85 & \pm & 0.04 & 3.96 & \pm & 0.02 \\
$\mathrm{Si}$ & 23.59 & 23.60 & \pm & 0.18 & 23.86 & \pm & 0.04 \\
$\mathrm{Ca}$ & 12.36 & 12.42 & \pm & 0.12 & 12.38 & \pm & 0.03 \\
$\mathrm{Ti}$ & 0.31 & 0.29 & \pm & 0.03 & 0.28 & \pm & 0.01 \\
$\mathrm{Cr}$ & 0.58 & 0.64 & \pm & 0.05 & 0.61 & \pm & 0.02 \\
$\mathrm{Fe}$ & 3.67 & 3.76 & \pm & 0.11 & 3.50 & \pm & 0.03 \\
$\mathrm{O}$ & 43.99 & 44.20 & \pm & 0.24 & 44.18 & \pm & 0.23 \\
$\Sigma$ & 99.50 & 99.81 & \pm & 0.29 & 99.90 & \pm & 0.31 \\
\hline
\end{tabular}

TABLE 2. Comparison of SDD-EDS analyses of K412 standard at different keV.

\begin{tabular}{crrrrr}
\hline \multicolumn{5}{c}{ SDD Element Weight \% } \\
El. & Actual & $15 \mathrm{kV}$ & $8 \mathrm{kV}$ & \multicolumn{1}{c}{$6 \mathrm{kV}^{1}$} & $6 \mathrm{kV}^{2}$ \\
\hline $\mathrm{Mg}$ & 11.66 & 11.73 & 11.65 & 11.94 & 11.93 \\
$\mathrm{Al}$ & 4.91 & 4.74 & 4.83 & 4.88 & 4.90 \\
$\mathrm{Si}$ & 21.20 & 21.15 & 21.21 & 21.04 & 21.15 \\
$\mathrm{Ca}$ & 10.87 & 10.89 & 11.00 & 11.01 & 11.12 \\
$\mathrm{Fe}$ & 7.57 & 7.83 & 7.82 & 12.17 & 7.75 \\
$\mathrm{O}$ & 42.96 & 43.82 & 43.31 & 43.30 & 43.99 \\
$\Sigma$ & 99.17 & 100.16 & 99.82 & 104.36 & 100.84 \\
\hline
\end{tabular}

${ }^{1} \mathrm{Fe} \mathrm{L} \alpha, \beta$ peak corrected for absorption using the mass absorption coefficient for Fe L $\alpha$.

${ }^{2} \mathrm{Fe} L \alpha, \beta$ peak corrected for using the average of mass absorption coefficients for $L \alpha$ and $L \beta$.

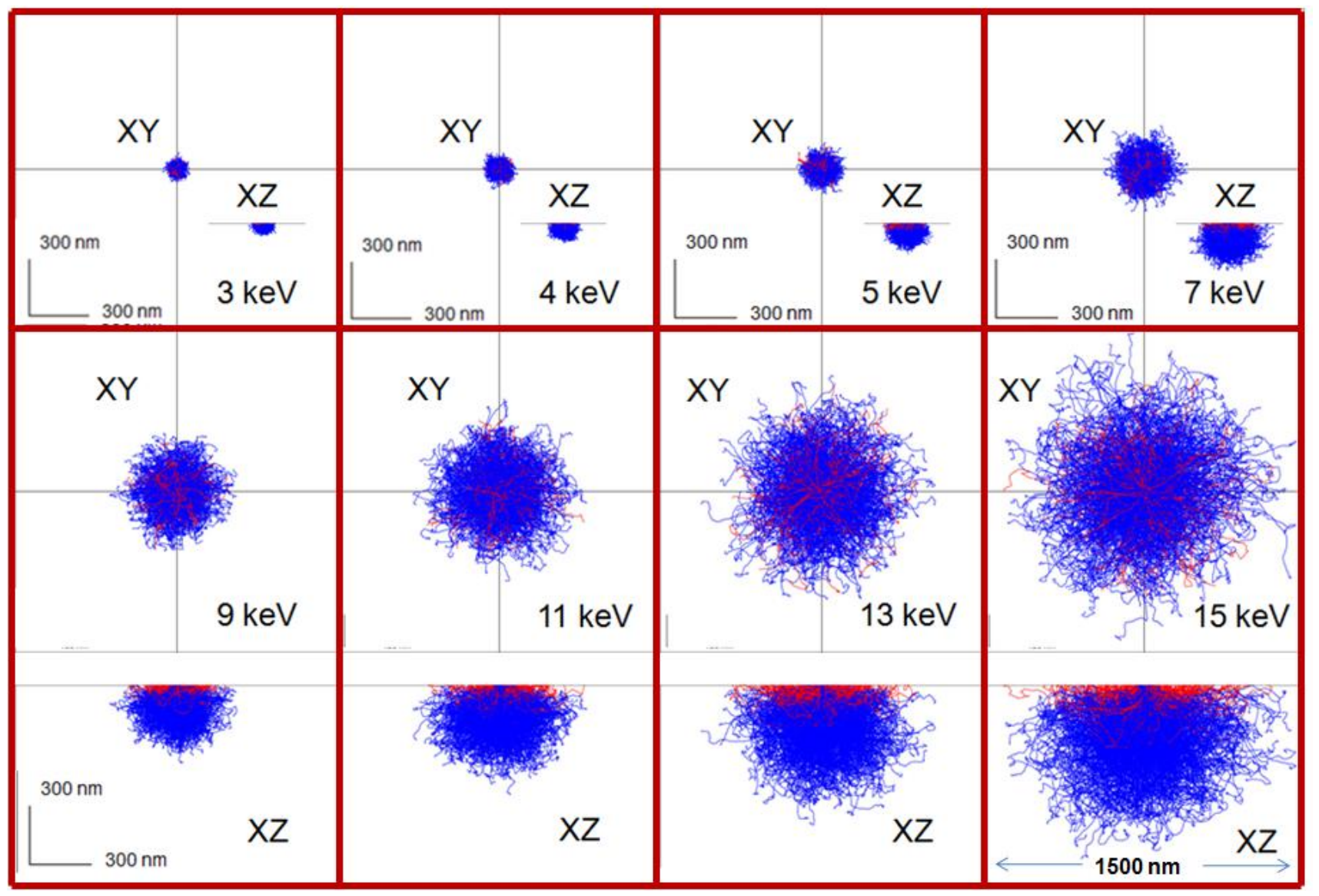

Fig. 1. Calculations of the electron excited volume in the xz (depth) and xy (radial) planes for Fe metal for a $40 \mathrm{~nm}$ electron probe with beam energies ranging from 3 to $15 \mathrm{keV}$. The $\mathrm{x}$-ray production volumes are a fraction of these depending on the $\mathrm{x}$-ray excitation energies. Calculations are based on Monte Carlo simulations using Mott scattering cross sections [4]. 